\title{
Base-Mediated Generation of Ketenimines from Ynamides: Addition of Hydrazones to Give Acetimidohydrazides
}

\author{
Capucine Mahe, ${ }^{[a, b]}$ Agathe C. A. D'Hollander ${ }^{[b]}$ and Kevin Cariou*[a] \\ [a] Chimie ParisTech, PSL University, CNRS Institute of Chemistry for Life and Health Sciences \\ Laboratory for Inorganic Chemical Biology 75005 Paris, France. kevin.cariou@cnrs.fr \\ [b] Université Paris-Saclay, CNRS Institut de Chimie des Substances Naturelles, LabEx LERMIT, UPR 230191198 , \\ Gif-sur-Yvette, France.
}

\begin{abstract}
Under basic conditions, $\mathrm{N}$-arylketenimines were generated in situ from $\mathrm{N}$-Boc ynamides and reacted with various hydrazones. Under heating, an addition of the hydrazine onto the central carbon of the ketenimines takes place giving rise to various acetimidohydrazides.
\end{abstract}

Ketenimines are the imino analogues of ketenes and, similarly, are highly reactive substrates, which often require the need to be formed in situ before reacting. ${ }^{[1-3]}$ One of the most widely used approach to generate ketenimines involves the combination of a sulfonylazide (such as tosylazide) and an alkyne, under copper catalysis, ${ }^{[4,5]}$ akin to azide-alkyne cycloaddition conditions (Scheme 1a). ${ }^{[6]}$ For our part, we have recently explored the conversion an ynamide ${ }^{[7-14]}$ into a ketenimine ${ }^{[15]}$ (including unsubstituted ones) and showed that they could be trapped by heterocyclic nucleophiles ${ }^{[16]}$ or undergo cycloaddition reactions with imines ${ }^{[17]}($ Scheme $1 b)$ and azallylanions (Scheme $\left.1 c\right) .{ }^{[18]}$ In this latter example, the basic reaction conditions served to generate both the ketenimine $\mathbf{2}$ and the aza-allyl anion $\mathbf{4}$ from the ynamide 1 and the imine 2, respectively. Under microwave heating the cycloaddition took place, giving rise to a series of 5-membered heterocycles. These results prompted us to explore the implementation of this strategy to trigger reactions with heterodipoles such as nitrones or hydrazones. Only few examples of [3+2] cycloadditions between $\mathrm{N}$-sulfonylketenimines (generated using copper catalysis) with heterodipoles such as, hydrazones ${ }^{[19]}$ or nitrones ${ }^{[20]}$ have been reported. We thus undertook the exploration of the reactivity of $\mathrm{N}-\mathrm{Boc}$ ynamides 1 as ketenimines precursor in the presence of various heterodipoles (Scheme 1d). 
a. Cu-catalyzed generation of $N$-Ts-ketenimines

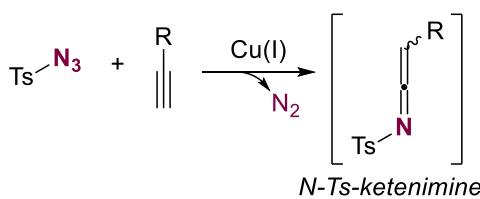

b. Generation of $N$-Ar-ketenimines from ynamides and [2+2] cycloaddition

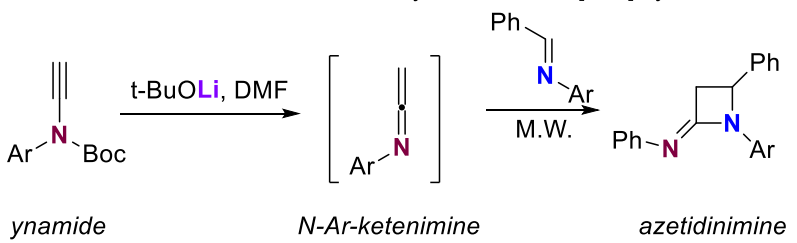

c. Generation of $\mathrm{N}-\mathrm{Ar}-$ ketenimines and [3+2] cycloaddition with azallylanions

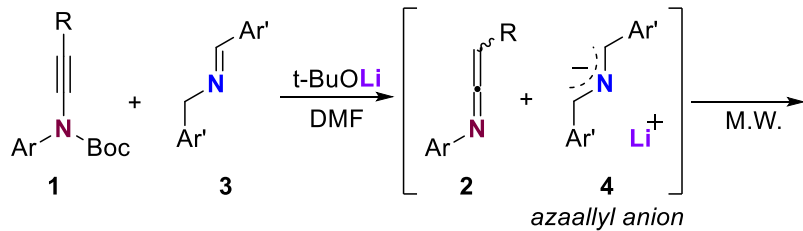

d. Generation of $\mathrm{N}$-Ar-ketenimines and reaction with heterodipoles ?

Scheme 1. Copper(I)-catalyzed formation of ketenimines (a) vs. generation of $\mathrm{N}$-Ar-ketenimines from ynamides (b); [3+2] cycloaddition with azallylanions (c) and objectives of the study (d).

We started our study with ynamide $1 \mathrm{a}(\mathrm{Ar}=\mathrm{Ph}$ and $\mathrm{R}=\mathrm{H})$ but, whatever the conditions employed (see SI for details), no identifiable adduct could be observed when the reaction was attempted with either nitrone $\mathbf{5}$ or $\mathrm{N}$-Ts- and $\mathrm{N}$-Ac-hydrazones $\mathbf{6 a}$ and $\mathbf{6 b}$, respectively (Scheme 2). Generally the heterodipole did not react or decomposed if the conditions were too harsh $\left(100^{\circ} \mathrm{C}\right.$, long reaction times), while the ketenimines seemed to be generated, as evidenced by the characterization of its adduct with dimethylamine coming from DMF. ${ }^{[18]}$

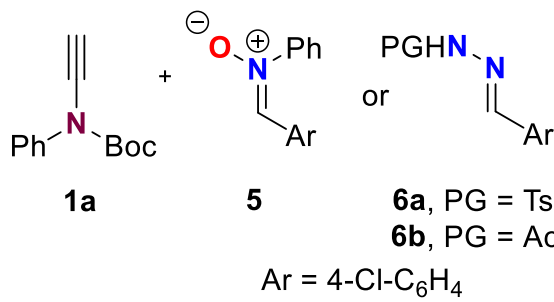

Scheme 2. First attempts with nitrones and tosylhydrazones.

These disappointing results led us to reconsider our design. While we had chosen an electron poor (4$\left.\mathrm{Cl}-\mathrm{C}_{4} \mathrm{H}_{6}\right)$ aryl on the electrophilic moiety of the heterodipole, we had not fully considered the relative lack of nucleophilicity of the other moiety. We thus turned our attention to $\mathrm{N}$-aryl rather than $\mathrm{N}$-tosyl or $\mathrm{N}$-acyl-hydrazones. Reacting equimolar amounts of hydrazone $\mathbf{6 c}$ and ynamide $1 \mathrm{a}$ at room temperature in DMF with 3 equivalents of $t$-BuOLi for $18 \mathrm{~h}$ allowed the formation of acetimidohydrazide 7ac in $30 \%$ yield (Table 1, entry 1). The formation of type of addition products had previously been reported using the copper-catalyzed generation of $N$-sulfonylketenimines. ${ }^{[21-23]}$ Further cyclization to a five-membered heteroaromatic derivative was only possible in a latter step using a $\mathrm{Zn}$ (II) catalyst and a stoichiometric amount of oxidant. ${ }^{[21]}$ As only the addition took place, a substoichiometric amount of 
Lewis acid $\left(\mathrm{ZnOAC}_{2}\right)$ was added, hoping it would improve the yield of the reaction ${ }^{[17]}$ and/or trigger the cyclization ${ }^{[21]}$ of 7ac, but no improvement were observed. On the contrary, after prolonged reaction time, decomposition of the reagents occurred (Entry 2). Raising the temperature to $100^{\circ} \mathrm{C}$ using a microwave heating for $1 \mathrm{~h}$ did raised the yield to $55 \%$, despite an incomplete conversion of the ynamide(Entry 3). Quite logically, increasing the amount of ynamide 1a (Entries 4 \& 5) did not have a positive effect on the outcome. However, increasing the amount of hydrazone $\mathbf{6 c}$ (and base) led to the formation of 7ac in $68 \%$ yield (Entry 6 ). This was further improved by running the reaction at $80^{\circ} \mathrm{C}$, and $86 \%$ of 7ac were isolated (Entry 7). Changing the ratio of reagents (Entry 8, 10), adding 10 mol\% of $\mathrm{ZnOAc}_{2}$ (Entry 9) or diminishing the amount of base (Entry 11) only had a detrimental effect on the reaction, which still proceed to give $63-76 \%$ yield of 7 ac.

Table 1. Optimization of the reaction conditions.

\begin{tabular}{|c|c|c|c|c|c|c|c|}
\hline & 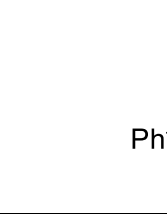 & $\begin{array}{l}+ \\
\text { Boc } 6 c\end{array}$ & $\underset{\mathrm{Ar}}{\stackrel{t-\mathrm{BuOLi}}{\mathrm{DMF}, \text { temp. }}}$ & 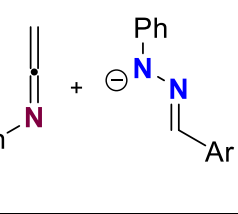 & & $\mathrm{Ph}^{-1}$ & ${ }_{\mathrm{Ar}}^{\mathrm{N}}$ \\
\hline Entry & $\begin{array}{l}\text { equiv. 1a/ } \\
\text { equiv. } 6 c\end{array}$ & $\begin{array}{l}t \text {-BuOLi } \\
\text { (equiv.) }\end{array}$ & Additive & Solvent $(0.2 \mathrm{M})$ & time & Temp. & Yield 7ac (\%) $)^{[a]}$ \\
\hline 1 & 1: 1 & 3.0 & none & DMF & $18 \mathrm{~h}$ & R.T. & $30^{[b]}$ \\
\hline 2 & 1: 1 & 3.0 & $\mathrm{Zn}(\mathrm{OAc})_{2}(10 \mathrm{~mol} \%)$ & DMF & $18 \mathrm{~h}$ & R.T. & c. m..$^{[b]}$ \\
\hline 3 & 1: 1 & 3.0 & none & DMF & $1 \mathrm{~h}$ & $100^{\circ} \mathrm{C}$ & $55^{[\mathrm{b}]}$ \\
\hline 4 & 1.5: 1 & 3.5 & none & DMF & $1 \mathrm{~h}$ & $100^{\circ} \mathrm{C}$ & $49^{[b]}$ \\
\hline 5 & 1.5: 1 & 4.0 & none & DMF & $1 \mathrm{~h}$ & $100^{\circ} \mathrm{C}$ & $55^{[b]}$ \\
\hline 6 & 1: 2 & 4.0 & none & DMF & $1 \mathrm{~h}$ & $100^{\circ} \mathrm{C}$ & 68 \\
\hline 7 & 1: 2 & 4.0 & none & DMF & $1 \mathrm{~h}$ & $80^{\circ} \mathrm{C}$ & 86 \\
\hline 8 & 1: 1 & 4.0 & none & DMF & $1 \mathrm{~h}$ & $80^{\circ} \mathrm{C}$ & $65^{[\mathrm{b}]}$ \\
\hline 9 & 1: 1 & 4.0 & $\mathrm{Zn}(\mathrm{OAc})_{2}(10 \mathrm{~mol} \%)$ & DMF & $1 \mathrm{~h}$ & $80^{\circ} \mathrm{C}$ & $63^{[\mathrm{b}]}$ \\
\hline 10 & 2: 1 & 4.0 & none & DMF & $1 \mathrm{~h}$ & $80^{\circ} \mathrm{C}$ & 65 \\
\hline 11 & 1: 1 & 3.5 & none & DMF & $1 \mathrm{~h}$ & $80^{\circ} \mathrm{C}$ & 76 \\
\hline
\end{tabular}

[a] Isolated yields. [b] The conversion of 1a was incomplete; c.m. = complex mixture.. 
Having determined the optimal reaction conditions, the scope of this transformation was then explored (Scheme 3). The first variations were brought to the ynamide partner. A chloride, a methoxy group or an iodide at the para position of the aryl ring Ar were well tolerated and the compounds $\mathbf{7 b c}-\mathbf{7 d c}$ were isolated with $94 \%, 76 \%$ and $54 \%$ yield, respectively. Electron-withdrawing groups $\left(\mathrm{CF}_{3}\right.$ and $\left.\mathrm{NO}_{2}\right)$, however, only led to complex mixtures, presumably because of the destabilization of the ketenimine intermediate. Ynamides bearing a bulky group (TIPS) or an aromatic (Ph) on the triple bond did not react, but an alkyl chain was well tolerated and 7 ec $(R=n-B u)$ was obtained in $86 \%$ yield. Various 4-chlorobenzaldehyde-derived $\mathrm{N}$-arylhydrazones were then reacted with ynamide 1a. Again, strong electronwithdrawing groups $\left(\mathrm{CF}_{3}\right.$ and $\left.\mathrm{NO}_{2}\right)$ were not compatible with the reaction conditions, but the adducts bearing an alkyl (7ad), a halogen (7ae, 7af) or an alkoxy (7ag) para substituent on the $N$-phenyl ring $\mathrm{Ar}^{1}$ were isolated in good yields (60-76\%). Finally, several example of aniline-derived hydrazones with diverse $\mathrm{Ar}^{2}$ groups were reacted with 1a.Phenyl, 4-anisyl (EDG), 4-trifluoromethanephenyl (EWG) as well as furanyl and thiophenyl rings (heteroaromatics) were found to be suitable for the reaction to proceed and yielded the corresponding acetimidohydrazides 7ah-7ak.
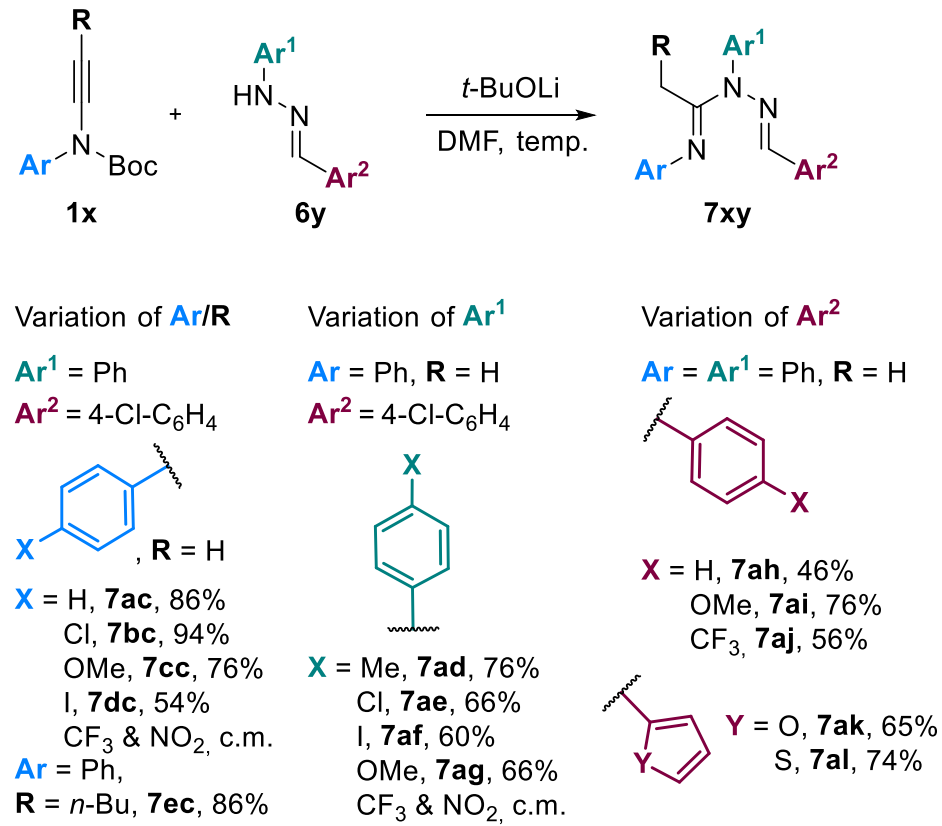

Scheme 3. Scope of the reaction

Despite many trials, with various Lewis acids and in the presence or absence of oxidants, ${ }^{[21]}$ the cyclization of adducts $\mathbf{7}$ into the corresponding pyrazoles was never observed. Nevertheless, it was possible to further derivatize these acetimidohydrazide, for example through a Pd-catalyzed SuzukiMiyaura cross-coupling reaction, to obtain biaryl 8 in XX\% yield (Scheme 4). 


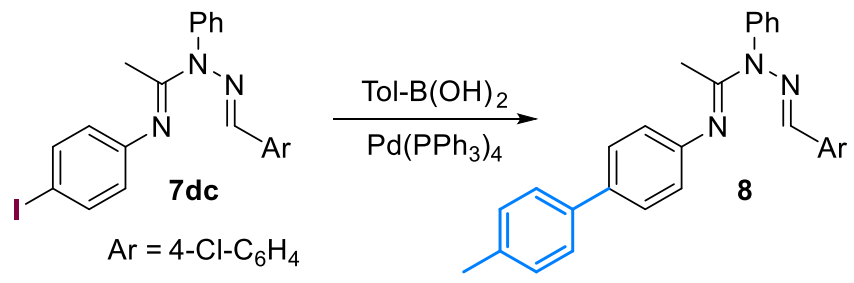

Scheme 4. Suzuki-Miyaura cross-coupling

Overall, we have been able to further explore the reactivity of ketenimines generated from ynamides, by reacting them with various heterodipoles. While nitrones and EWG-susbtituted hydrazones were found to be incompatible with the reaction conditions, $N$-arylhydrazones were suitable reacting partners. This led to the formation of diversely substituted acetimidohydrazides in good to excellent yields. Future studies will be directed to the explore the reactivity and potential bioactivity of these nitrogen-rich compounds that can be viewed as "open" pyrazoles, a motif that holds considerable interest in the development of pharmaceutical compounds. ${ }^{[24,25]}$

\section{Acknowledgements}

The authors acknowledge the support of the CNRS and Chimie ParisTech. C.M. thanks MESRI (ParisSaclay University) for a Ph.D. fellowship and A.C.A.D. thanks the Laboratory of Excellence in Research on Medication and Innovative Therapeutics (LERMIT, grant ANR-10-LABX-33 under the program Investissements d'Avenir ANR-11-IDEX-0003-01) for a postdoctoral fellowship.

Keywords: ynamides $\bullet$ ketenimines $\bullet$ hydrazones $\bullet$ acetimidohydrazide

\section{References}

[1] P. Lu, Y. Wang, Chem. Soc. Rev. 2012, 41, 5687-5705.

[2] M. Alajarin, M. Marin-Luna, A. Vidal, Eur. J. Org. Chem. 2012, 2012, 5637-5653.

[3] A. D. Allen, T. T. Tidwell, Chem. Rev. 2013, 113, 7287-7342.

[4] I. Bae, H. Han, S. Chang, J. Am. Chem. Soc. 2005, 127, 2038-2039.

[5] M. Whiting, V. V. Fokin, Angew. Chem. Int. Ed. 2006, 45, 3157-3161.

[6] J. E. Hein, V. V. Fokin, Chem. Soc. Rev. 2010, 39, 1302-1315.

[7] G. Evano, A. Coste, K. Jouvin, Angew. Chem. Int. Ed. 2010, 49, 2840-2859.

[8] K. A. DeKorver, H. Li, A. G. Lohse, R. Hayashi, Z. Lu, Y. Zhang, R. P. Hsung, Chem. Rev. 2010, 110, 5064-5106. 
[9] X.-N. Wang, H.-S. Yeom, L.-C. Fang, S. He, Z.-X. Ma, B. L. Kedrowski, R. P. Hsung, Acc. Chem. Res. 2014, 47, 560-578.

[10] B. Zhou, T.-D. Tan, X.-Q. Zhu, M. Shang, L.-W. Ye, ACS Catal. 2019, 9, 6393-6406.

[11] Y.-B. Chen, P.-C. Qian, L.-W. Ye, Chem. Soc. Rev. 2020, 49, 8897-8909.

[12] C. C. Lynch, A. Sripada, C. Wolf, Chem. Soc. Rev. 2020, 49, 8543-8583.

[13] F.-L. Hong, L.-W. Ye, Acc. Chem. Res. 2020, 53, 2003-2019.

[14] C. Mahe, K. Cariou, Adv. Synth. Catal. 2020, 362, 4820-4832.

[15] R. H. Dodd, K. Cariou, Chem. - Eur. J. 2018, 24, 2297-2304.

[16] A. Hentz, P. Retailleau, V. Gandon, K. Cariou, R. H. Dodd, Angew. Chem. Int. Ed. 2014, 126, 8473-8477.

[17] E. Romero, C. Minard, M. Benchekroun, S. Ventre, P. Retailleau, R. H. Dodd, K. Cariou, Chem. - Eur. J. 2017, 23, 12991-12994.

[18] Agathe C. A. D’Hollander, Eugénie Romero, Kamsana Vijayakumar, Camille le Houérou, Pascal Retailleau, Robert H. Dodd, Bogdan I. Iorga, Kevin Cariou, 2020, DOI 10.26434/chemrxiv.13105571.v1.

[19] S. Li, Y. Luo, J. Wu, Org. Lett. 2011, 13, 4312-4315.

[20] K. Namitharan, K. Pitchumani, Org. Lett. 2011, 13, 5728-5731.

[21] Y. Li, D. Hong, Y. Zhu, P. Lu, Y. Wang, Tetrahedron 2011, 67, 8086-8091.

[22] V. Mahendran, S. Shanmugam, RSC Adv. 2015, 5, 20003-20010.

[23] V. Mahendran, S. Shanmugam, RSC Adv. 2015, 5, 92473-92479.

[24] J. V. Faria, P. F. Vegi, A. G. C. Miguita, M. S. dos Santos, N. Boechat, A. M. R. Bernardino, Bioorg. Med. Chem. 2017, 25, 5891-5903.

[25] K. Karrouchi, S. Radi, Y. Ramli, J. Taoufik, Y. N. Mabkhot, F. A. Al-aizari, M. Ansar, Molecules 2018, 23, 134.

\section{Graphical Abstract}

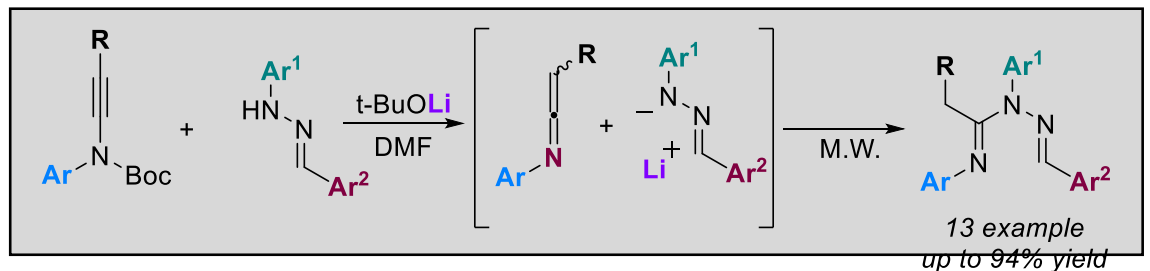

